\title{
Important of Pomegranates in Iran
}

\author{
Hamid kheyrodin ${ }^{1}$, Sadafkheyrodin ${ }^{2}$ \\ ${ }^{1}$ Assistant professor in semnan university -Iran \\ ${ }^{2}$ MS.c student in urban planning in Mashadazad University - Iran
}

\author{
*Corresponding Author: Hamid kheyrodin, Assistant professor in semnan university -Iran. \\ Email: kheyrodin@semnan.ac.ir
}

\begin{abstract}
Pomegranates have healthy amounts of fiber to help keep your system regulated, and are one of the fruits nutritionists suggest for weight loss and cholesterol level control, while at the same time boosting immunity, improving circulation, and offering cancer protection. In addition, they do protect against cancer, as numerous studies indicate. Low in saturated fat and cholesterol, pomegranates are an excellent source of vitamin C, providing $48 \%$ of the daily recommended value and $58 \%$ of what's needed from vitamin K. Chockfull of minerals, they provide high amounts of copper, potassium, folate, manganese, thiamin, pantothenic acid (vitamin B5), and pyridoxine, with ample amounts of antioxidant polyphenols thrown in. Three such polyphenols are tannins, anthocyanins, and ellagic acid. While most fruits contain some, fresh pomegranate juice has all three, as well as the antioxidant punicalagin, which research indicates may be effective in reducing the risk of heart disease due to aggressive free radical-scavenging activities in the body. In Iran, there are a variety of pomegranates Myatadzhy, Gissarskii, Kara BalaMiursal. But the popular pomegranate cultivarsnsaveh and semnan and shiraz pomegranate.
\end{abstract}

Key words: Pomegranate, Iran, Vitamin c.

\section{INTRODUCTION}

Pomegranate (Punicagranatum L.), from family Punicaceae, has been traditionally used for thousands of years as a medicinal fruit Fig.1. Mediterranean regions (including Iran, India and Pakistan) have the highest rate of pomegranate cultivation in the world. Based on excavations of the Early Bronze Age (3500-2000 BC), it is believed that the pomegranate was one of the first cultivated fruits for its beneficial properties. Pomegranate was held sacred by many of the world's major religions and nations. In the Holy Quran, pomegranate has been described as a paradise fruit and a symbol of insurgence and life everlasting in Christian art. In China, pomegranate is widely represented in art symbolizing fertility, posterity, abundance, numerous and virtuous offspring, and a blessed future. It was also a symbol of invincibility in battle by the Persians ${ }^{7-9}$. For over 4,000 years, human beings have cultivated pomegranate for its medicinal properties. Juice, seeds, leaves, flowers, bark and roots of pomegranate have various effects. Lowering fever, treating diabetes, anthelmintic, anti-diarrhea, blood tonic, stopping the bleeding, and healing ulcers are the most important traditional uses of pomegranate ${ }^{10-14}$.

What kind of fruit is a pomegranate; what are its growth characteristics?

The pomegranate (Punicagranatum) is a shrub or a small tree up to 8 meters high (most are considerably smaller) that is evergreen in the tropics and deciduous in the subtropics and temperate zones. The pomegranate plant is more or less spiny, deciduous, with small, narrow, oblong leaves with short stems. The trunk is covered by a red-brown bark which later becomes gray. Branches are stiff, angular and often spiny. There is a strong tendency to sucker from the base, which gives rise to the bush or shrub form of growth. In orchards, plants are normally trained to a single trunk, forming a large shrub or small tree. Trees may be trained to multiple trunks in colder areas, to reduce risk of total tree loss. While pomegranates may live as long as 200 years, vigor declines after about 15 years and the plant becomes non-productive. Most pomegranates begin fruiting in their second year (some in the first year), but substantial bearing does not begin until 3-5 years. Flowers may be white, pink, red or orange. Flowers may be male (with a few atrophied ovules) or 'perfect', containing both male and female parts and producing the crop. Most pomegranates are self- fertile, although they will set a 
better crop if another cultivar is available for cross-pollination; fruit set has been increased $38 \%$ with cross pollination. A few pomegranates are not self-fertile and require compatible pollenizers. Pollination is by insects, usually honey bees. Normal flowering of pomegranate varieties occurs, in general, between March-April and July-August. The pomegranate, botanical name Punicagranatum, is a fruit-bearing deciduous shrub or small tree in the family Lythraceae that grows between 5 and $8 \mathrm{~m}$ (16 and $26 \mathrm{ft}$ ) tall. The fruit is typically in season in the Northern Hemisphere from September to February, and in the Southern Hemisphere from March to May. As intact arils or juice, pomegranates are used in baking, cooking, juice blends, meal garnishes, smoothies, and alcoholic beverages, such as cocktails and wine. The pomegranate originated in the region of modern-day Iran, and has been cultivated since ancient times throughout the Mediterranean region and northern India. It was introduced into Spanish America in the late 16th century and into California by Spanish settlers in 1769. Today, it is widely cultivated throughout the Middle East and Caucasus region, north and tropical Africa, the Indian subcontinent, Central Asia, the drier parts of southeast Asia, and parts of the Mediterranean Basin. ${ }^{[3]}$ It is also cultivated in parts of Arizona and California. ${ }^{[4]}$ In the 20th and $21 \mathrm{st}$ centuries, it became more common in the commercial markets of Europe and the Western Hemisphere.

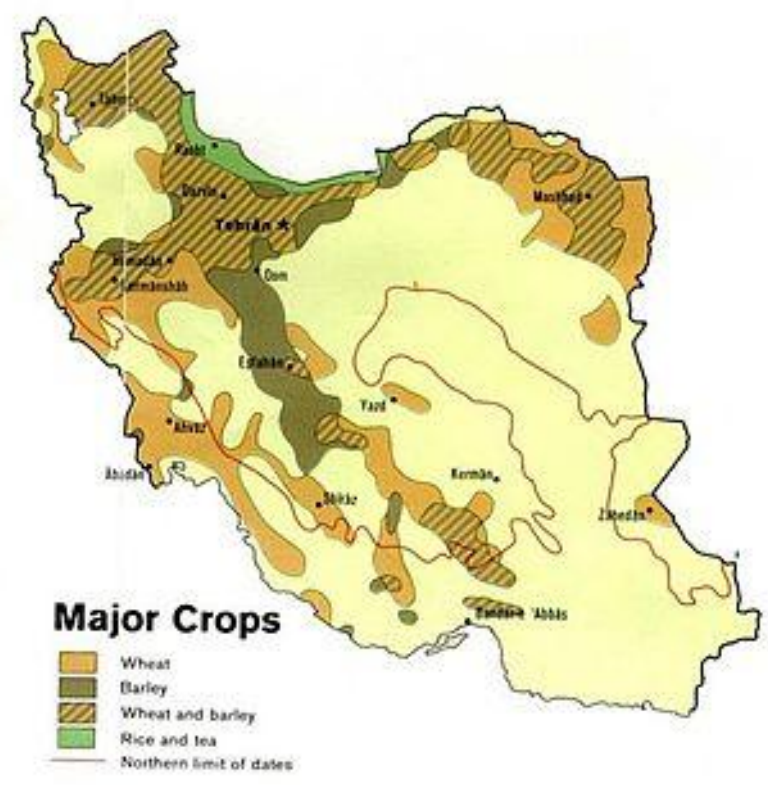

Fig1. Major crops cultivation in Iran

Table1. Most Important Pharmacologic Compounds of Punica Granatum L. $\underline{10}, \underline{11}, \underline{27-29}$

\begin{tabular}{|l|l|l|}
\hline \multicolumn{1}{|c|}{ Chemical class } & \multicolumn{1}{|c|}{ Compound(s) name } & \multicolumn{1}{c|}{ Part(s) of the plant } \\
\hline Simple sugars & Glucose, Fructose, Sucrose & Juice \\
\hline Aliphatic organic acids & Citric acid, Malic acid, Tartaric acid & Juice \\
\hline Hydroxybenzoic acids & $\begin{array}{l}\text { Gallic acid, Ellagic acid, 3,3_-Di-O-methylellagic } \\
\text { acid }\end{array}$ & Juice, Leaf, Flower, Seed \\
\hline Flavan-3-ols & Flavan-3-ol, Catechin, Epicatechin & Juice, Leaf \\
\hline Flavonol glycosides & $\begin{array}{l}\text { Kaempferol 3-O-glycoside, Kaempferol3- } O \text { - } \\
\text { rhamnoglycoside }\end{array}$ & Leaf \\
\hline Anthocyanidins & Delphinidin, Cyanidin & Leaf \\
\hline Ellagitannins & Punicalin, Punicalagin, Corilagin & Leaf \\
\hline Amino acids & Proline, Valine, Methionine & Juice \\
\hline Conjugated fatty acids & Punicic acid & Seed \\
\hline $\begin{array}{l}\text { Non-conjugated fatty } \\
\text { acids }\end{array}$ & Linoleic acid, Oleic acid, Palmitic acid & Seed \\
\hline Sterols & Daucosterol, Camesterol & Seed \\
\hline Sex steroids & 17 -_-Estradiol, Testosterone & Seed \\
\hline $\begin{array}{l}\text { Phenyl aliphatic } \\
\text { glycosides }\end{array}$ & Icariside D1 & Seed \\
\hline
\end{tabular}




\section{ETymology a Pomegranate}

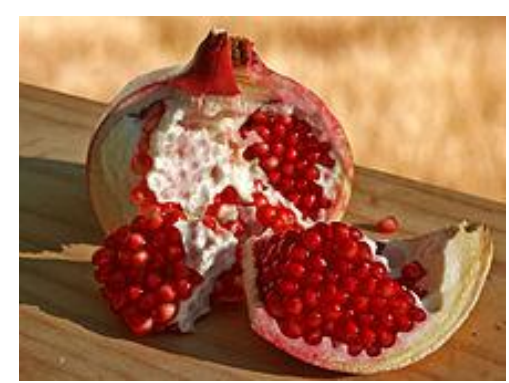

Fig2. An opened pomegranate

The name pomegranate derives from Medieval Latinpōmum "apple" and grānātum "seeded". ${ }^{[5]}$ Possibly stemming from the old French word for the fruit, pomme-grenade, the pomegranate was known in early English as "apple of Grenada" - a term which today survives only in heraldic blazons. This is a folk etymology, confusing the Latin granatus with the name of the Spanish city of Granada, which derives from Arabic. ${ }^{[6]}$

Garnet derives from Old French grenat by metathesis, from Medieval Latin granatum as used in a different meaning "of a dark red color". This derivation may have originated from pomum granatum, describing the color of pomegranate pulp, or from granum, referring to "red dye, cochineal". ${ }^{7]}$

The French term for pomegranate, grenade, has given its name to the military grenade. ${ }^{[8]}$

A pomegranate shrub growing in the Draa River valley of southern Morocco.

A shrub or small tree growing 6 to $10 \mathrm{~m}$ (20 to $33 \mathrm{ft}$ ) high, the pomegranate has multiple spiny branches and is extremely long-lived, with some specimens in France surviving for 200 years. ${ }^{[3]} \mathrm{P}$. granatum leaves are opposite or sub opposite, glossy, narrow oblong, entire, 3-7 cm (1.2-2.8 in) long and $2 \mathrm{~cm}$ broad. The flowers are bright red and $3 \mathrm{~cm}$ in diameter, with three to seven petals. ${ }^{[3]}$ Some fruitless varieties are grown for the flowers alone.

The edible fruit is a berry, intermediate in size between a lemon and a grapefruit, 5-12 cm (2.04.7 in) in diameter with a rounded shape and thick, reddish skin. ${ }^{[3]}$ The number of seeds in a pomegranate can vary from 200 to about $1400 .{ }^{[9]}$ Each seed has a surrounding water-laden pulp - the edible sarcotesta that forms from the seed coat - ranging in color from white to deep red or purple. The seeds are "exarillate", i.e., unlike some other species in the order, Myrtales, no aril is present. The sarcotesta of pomegranate seeds consists of epidermis cells derived from the integument. ${ }^{[10]}$ The seeds are embedded in a white, spongy, astringent membrane. ${ }^{[3]}$ Pomegranate juice, obtained by compressing the seeds, causes a deep red stain which is difficult to remove. ${ }^{[1]}$ The pigmentation of pomegranate juice results from the presence of anthocyanins and ellagitannins. ${ }^{[12]}$

\section{Cultivation}

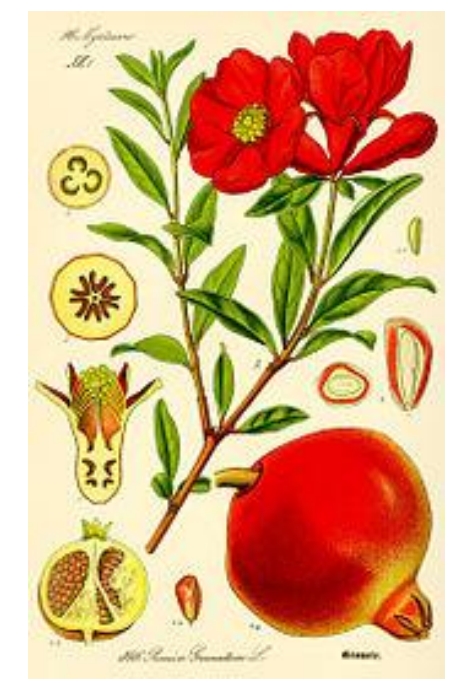

Fig3. Illustration by Otto Wilhelm Thomé, 1885 
P. granatum is grown for its fruit crop, and as ornamental trees and shrubs in parks and gardens. Mature specimens can develop sculptural twisted-bark multiple trunks and a distinctive overall form. Pomegranates are drought-tolerant, and can be grown in dry areas with either a Mediterranean winter rainfall climate or in summer rainfall climates. In wetter areas, they can be prone to root decay from fungal diseases. They can be tolerant of moderate frost, down to about $-12{ }^{\circ} \mathrm{C}\left(10^{\circ} \mathrm{F}\right)$.

Insect pests of the pomegranate can include the pomegranate butterfly Viracholaisocrates and the leaffooted bug Leptoglossuszonatus, and fruit flies and ants are attracted to unharvested ripe fruit. Pomegranate grows easily from seed, but is commonly propagated from 25 to $50 \mathrm{~cm}$ (9.8 to $19.7 \mathrm{in}$ ) hardwood cuttings to avoid the genetic variation of seedlings. Air layering is also an option for propagation, but grafting fails.

Table2. Common and Important Fatty Acids Found In Pso in Various Types of Pomegranate. Results Are Expressed As Average (Percentage Of Total Fatty Acids) \pm Standard Deviation.

\begin{tabular}{|l|l|l|l|}
\hline \multicolumn{1}{|c|}{ Fatty Acids } & \multicolumn{1}{c|}{ India Strain } & \multicolumn{1}{c|}{ China Strain } & \multicolumn{1}{c|}{ Turkey Strain } \\
\hline $16: 0$ & $5.7 \pm 4.1$ & $5.07 \pm 1.30$ & $2.45 \pm 0.19$ \\
\hline $18: 0$ & $2.1 \pm 3.1$ & $4.20 \pm 1.56$ & $1.52 \pm 0.26$ \\
\hline $18: 1(\omega-9)$ & $9.0 \pm 5.6$ & $7.86 \pm 2.25$ & $4.19 \pm 0.61$ \\
\hline $18: 2(\omega-6)$ & $10.8 \pm 6.9$ & $8.36 \pm 2.36$ & $4.49 \pm 0.49$ \\
\hline $18: 3(9 c 11 t 13 t)$ & & $10.70 \pm 4.44$ & $6.41 \pm 0.27$ \\
\hline $18: 3(9 t 11 t 13 t)$ & & $8.78 \pm 5.16$ & $1.03 \pm 0.16$ \\
\hline $18: 3(9 t 11 t 13 c)$ & & $15.24 \pm 6.17$ & $3.48 \pm 0.34$ \\
\hline $18: 3(9 c 11 t 13 c)$ & $71.5 \pm 17.9$ & $36.98 \pm 10.12$ & $74.11 \pm 1.55$ \\
\hline
\end{tabular}

Table3. Fatty Acid Composition of Pso in Iranian Strains of Pomegranate.

\begin{tabular}{|l|l|l|l|l|l|l|}
\hline \multirow{2}{*}{ Variety } & \multicolumn{7}{c|}{ Fatty acid (\%) } \\
\cline { 2 - 7 } & $\mathbf{1 8 : 3}$ & $\mathbf{1 8 : 2}$ & $\mathbf{1 8 : 1}$ & $\mathbf{1 8 : 0}$ & $\mathbf{1 6 : 0}$ & Others \\
\hline Red Seed Ardestani & 79.43 & 6.95 & 6.62 & 2.09 & 3.16 & 1.72 \\
\hline Rizdavar`sDorpaye & 79.22 & 6.87 & 6.30 & 2.50 & 3.36 & 1.73 \\
\hline Ashkzar`s Sour Narak & 82.40 & 5.22 & 5.71 & 1.99 & 2.95 & 1.70 \\
\hline Taft`s Tokhm-e Mush & 78.25 & 6.59 & 7.48 & 2.54 & 3.41 & 1.70 \\
\hline Chatrud`s Sour Shahi & 78.73 & 7.08 & 6.68 & 2.16 & 3.57 & 1.75 \\
\hline
\end{tabular}

\subsection{Varieties}

P. granatumvar. nana is a dwarf variety of P. granatum popularly planted as an ornamental plant in gardens and larger containers, and used as a bonsai specimen tree. It could well be a wild form with a distinct origin. It has gained the Royal Horticultural Society's Award of Garden Merit. ${ }^{[15]}$ The only other species in the genus Punica is the Socotran pomegranate (P. protopunica), which is endemic to the island of Socotra. It differs in having pink (not red) flowers and smaller, less sweet fruit.

\subsection{Cultivars}

P. granatum has more than 500 named cultivars, but evidently has considerable synonymy in which the same genotype is named differently across regions of the world. ${ }^{[17]}$

Several characteristics between pomegranate genotypes vary for identification, consumer preference, preferred use, and marketing, the most important of which are fruit size, exocarp color (ranging from yellow to purple, with pink and red most common), seed-coat color (ranging from white to red), hardness of seed, maturity, juice content and its acidity, sweetness, and astringency.

\subsection{Cultural History}

Pomegranate is native to a region from Iran to northern India. ${ }^{[3]}$ Pomegranates have been cultivated throughout the Middle East, South Asia, and Mediterranean region for several millennia, and also thrive in the drier climates of California and Arizona. ${ }^{[3][18][19]}$ Carbonized exocarp of the fruit has been identified in early Bronze Age levels of Jericho in the West Bank, as well as late Bronze Age levels of Hala Sultan Tekke on Cyprus and Tiryns. A large, dry pomegranate was found in the tomb of Djehuty, the butler of Queen Hatshepsut in Egypt; Mesopotamiancuneiform records mention pomegranates from the mid-third millennium $\mathrm{BC}$ onwards. 


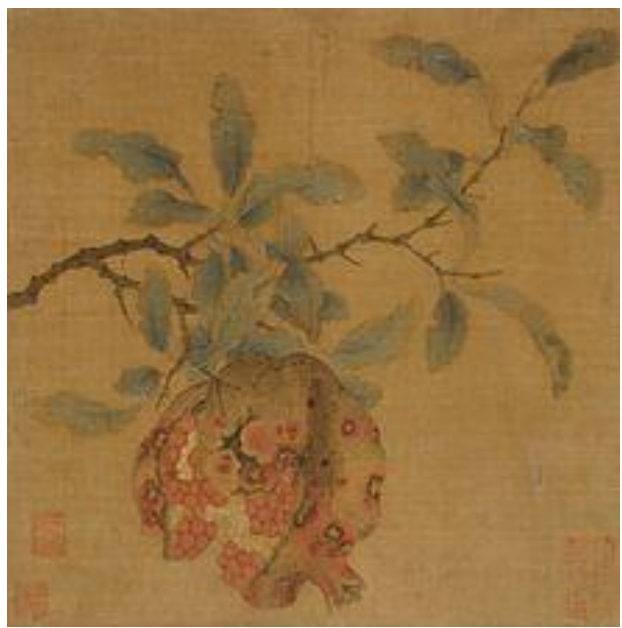

Fig4. Pomegranate, late Southern Song dynasty or early Yuan dynastycirca 1200-1340 (Los Angeles County Museum of Art)

It is also extensively grown in South China and in Southeast Asia, whether originally spread along the route of the Silk Road or brought by sea traders. Kandahar is famous in Afghanistan for its highquality pomegranates. Although not native to Korea or Japan, the pomegranate is widely grown there and many cultivars have been developed. It is widely used for bonsai because of its flowers and for the unusual twisted bark the older specimens can attain the term "balaustine" (Latin: balaustinus) is also used for a pomegranate-red color.

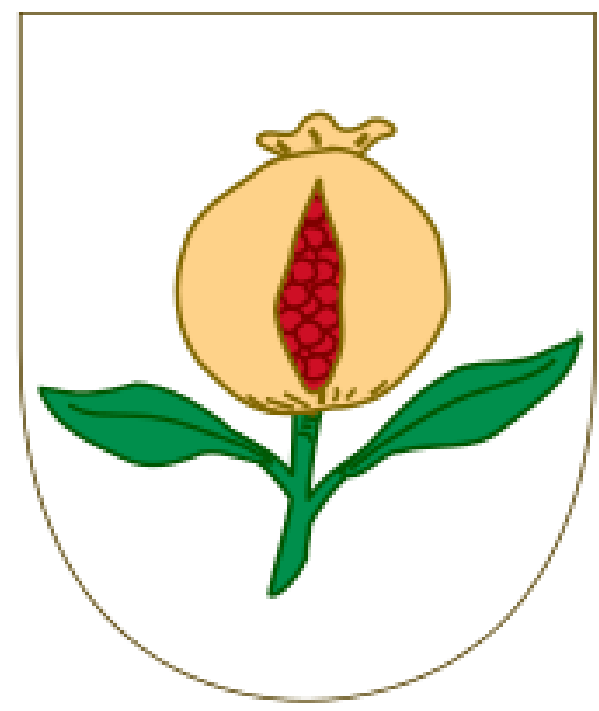

Fig5. Coat of Arms of Granada

The ancient city of Granada in Spain was renamed after the fruit during the Moorish period and today the province of Granada uses pomegranate as a charge in heraldry for its canting arms. [citation needed]

Spanish colonists later introduced the fruit to the Caribbean and America (Spanish America), but in the English colonies, it was less at home: "Don't use the pomegranate inhospitably, a stranger that has come so far to pay his respects to thee," the English QuakerPeter Collinson wrote to the botanizing John Bartram in Philadelphia, 1762. "Plant it against the side of thy house; nail it close to the wall. In this manner it thrives wonderfully with us and flowers beautifully, and bears fruit this hot year. I have twenty-four on one tree... Doctor Fothergill says, of all trees this is most salutiferous to mankind."The pomegranate had been introduced as an exotic to England the previous century, by John Tradescant the elder, but the disappointment that it did not set fruit there led to its repeated introduction to the American colonies, even New England. It succeeded in the South: Bartram received a barrel of pomegranates and oranges from a correspondent in Charleston, South Carolina, 1764. John Bartram partook of "delitious" pomegranates with Noble Jones at Wormsloe Plantation, near Savannah, Georgia, in September 1765. Thomas Jefferson planted pomegranates at Monticello in 1771: he had them from George Wythe of Williamsburg. ${ }^{[26]}$ 


\subsection{Culinary Use}

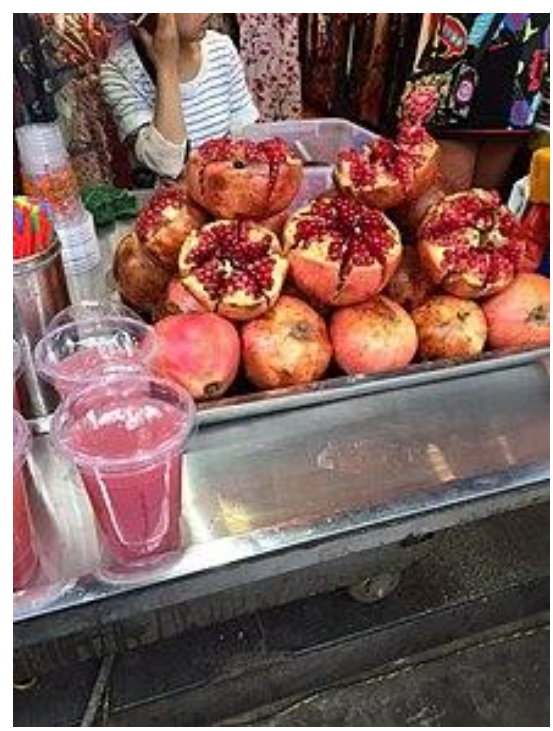

Fig6. A stall selling pomegranate juice in Xi'an, China

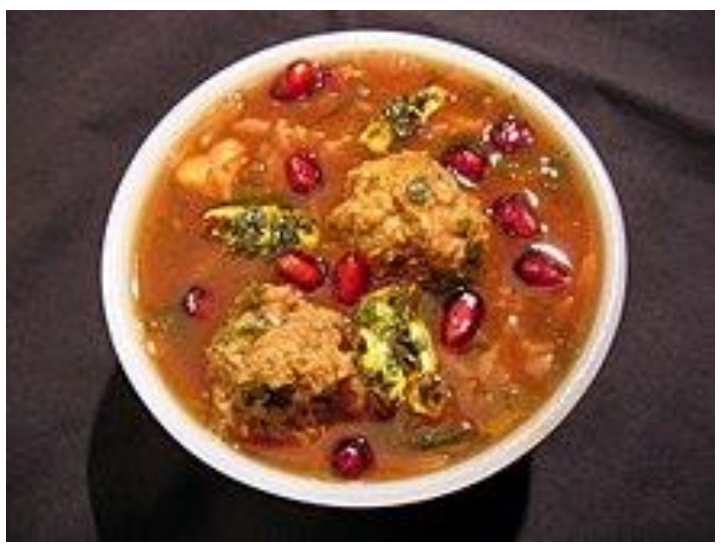

Fig7. A bowl of ash-e anar, a Persian soup made with pomegranate juice

After the pomegranate is opened by scoring it with a knife and breaking it open, the seeds are separated from the peel and internal white pulp membranes. Separating the seeds is easier in a bowl of water because the seeds sink and the inedible pulp floats. Freezing the entire fruit also makes it easier to separate. Another effective way of quickly harvesting the seeds is to cut the pomegranate in half, score each half of the exterior rind four to six times, hold the pomegranate half over a bowl, and smack the rind with a large spoon. The seeds should eject from the pomegranate directly into the bowl, leaving only a dozen or more deeply embedded seeds to remove. The entire seed is consumed raw, though the watery, tasty sarcotesta is the desired part. The taste differs depending on the variety or cultivar of pomegranate and its ripeness. ${ }^{\text {[itation needed] }}$

Pomegranate juice can be sweet or sour, but most fruits are moderate in taste, with sour notes from the acidic ellagitannins contained in the juice. Pomegranate juice has long been a popular drink in Europe, the Middle East and is now widely distributed in the United States and Canada.

Grenadine syrup long ago consisted of thickened and sweetened pomegranate juice, now is usually a sales name for syrup based on various berries, citric acid, and food coloring, mainly used in cocktail mixing. In Europe, Bols still manufactures grenadine syrup with pomegranate. ${ }^{[29]}$ Before tomatoes, a New World fruit, arrived in the Middle East, pomegranate juice, molasses, and vinegar were widely used in many Iranian foods, and are still found in traditional recipes such as fesenjān, a thick sauce made from pomegranate juice and ground walnuts, usually spooned over duck or other poultry and rice, and in ash-e anar (pomegranate soup).

Pomegranate seeds are used as a spice known as anardana (from Persian: anar + dana, pomegranate + seed), most notably in Indian and Pakistani cuisine. Dried whole seeds can often be obtained in ethnic Indian subcontinent markets. These seeds are separated from the flesh, dried for 10-15 days, and used 
as an acidic agent for chutney and curry preparation. Ground anardana is also used, which results in a deeper flavoring in dishes and prevents the seeds from getting stuck in teeth. Seeds of the wild pomegranate variety known as daru from the Himalayas are regarded as high quality sources for this spice. Dried pomegranate seeds, found in some natural specialty food markets, still contain some residual water, maintaining a natural sweet and tart flavor. Dried seeds can be used in several culinary applications, such as trail mix, granola bars, or as a topping for salad, yogurt, or ice cream.

In the Caucasus, pomegranate is used mainly for juice. ${ }^{[32]}$ In Azerbaijan, a sauce from pomegranate juice narsharab, (from Persian: (a) nar + sharab, lit. "Pomegranate wine") is usually served with fish or tikakabab. In Turkey, pomegranate sauce (Turkish: nar ekşisi) is used as a salad dressing, to marinate meat, or simply to drink straight. Pomegranate seeds are also used in salads and sometimes as garnish for desserts such as güllaç. ${ }^{[3]}$ Pomegranate syrup or molasses is used in muhammara, a roasted red pepper, walnut, and garlic spread popular in Syria and Turkey. In Greece, pomegranate (Greek: pó $\delta$, rodi) is used in many recipes, including kollivozoumi, a creamy broth made from boiled wheat, pomegranates, and raisins, legume salad with wheat and pomegranate, traditional Middle Eastern lamb kebabs with pomegranate glaze, pomegranate eggplant relish, and avocado-pomegranate dip. Pomegranate is also made into a liqueur, and as a popular fruit confectionery used as ice cream topping, mixed with yogurt, or spread as jam on toast. In Cyprus and Greece, and among the

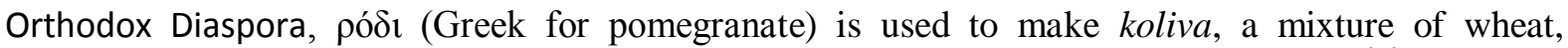
pomegranate seeds, sugar, almonds, and other seeds served at memorial services. ${ }^{\text {[citation needed] }}$

In Mexico, they are commonly used to adorn the traditional dish chiles en nogada, representing the red of the Mexican flag in the dish which evokes the green (poblano pepper), white (nogada sauce) and red (pomegranate seeds) tricolor

\section{EFFECTS ON INSULIN RESISTANCE}

TNF- $\alpha$ is one of the most important pro-inflammatory cytokines which plays a pivotal role in obesity, inflammation and insulin resistance. Higher serum levels of TNF- $\alpha$ are accompanied with insulin resistance. Anusree et al. showed that TNF- $\alpha(10 \mathrm{ng} / \mathrm{mL}$ for $24 \mathrm{hr})$ decreased 1.7 fold in insulin stimulated glucose uptake with respect to control group in 3T3-L1 adipocytes, but PA with doses of 5, $10,30 \mu \mathrm{M}$ restored the glucose uptake capacity significantly and dose- dependently. PA at dose of $30 \mu \mathrm{M}$ is comparable to rosiglitazone $(100 \mathrm{nM})$ in insulin stimulated glucose uptake. The similar condition was observed in production of ROS with the effect of TNF- $\alpha$ and its restoration with the effect of PA. TNF- $\alpha$ treatment caused significant alterations in mitochondrial trans-membrane potential, reduction in ATP production, $\mathrm{O}_{2}$ consumption, overall increase in cellular ROS generation and a decrease in aconitase activity. The use of PA restored these states to the baseline.

Peroxisome proliferators' activated receptor $\gamma$ (PPAR- $\gamma$ ) agonists increase mitochondrial biogenesis and normalize the fission fusion ratio in this organelle that be altered with inflammation and high levels of TNF- $\alpha$.. Agonistic effects of PA on PPAR- $\gamma$, lowering oxidative stress and serum TNF- $\alpha$ levels and positive effects of PA on mitochondrial functions are the main anti-diabetic mechanisms of PSO..

Effects of PSO on obesity and insulin resistance induced by rich fat diet in mice showed that, rich fat diet with $1 \%$ PSO after 12 weeks induced higher peripheral insulin sensitivity in treated group compared to control group ( $164 \pm 52 \%$ vs. $92 \pm 24 \%$ respectively), but liver insulin sensitivity showed no significant difference between two groups. In this study, obesity and fat deposition induced by this regimen was ameliorated by PSO, significantly. A similar study was performed by Miranda et al. That used diet with $0.5 \% \mathrm{PA}$ in rats. The results of this study showed no changes in adipose tissue weights and insulin resistance, but the glycemic value in the PA group had decreased, significantly. Improvement in insulin sensitivity is associated with reducing the risk of developing type 2diabetes. Insulin sensitivity was improved with $61.79 \mathrm{mg} /$ day PSO in mice which was treated with rich fat regimen compared to control group. In addition, final body weight, body weight accumulation, serum adiponectin, serum leptin, and serum insulin were reduced in treated group.

The use of PSO (200 and 400mg/day for 28 days) in streptozocin-nicotinamide induced diabetic rats showed that serum insulin levels increased but the serum glucose level had no change. Up-regulation of PPAR- $\gamma$ responsive genes by PA may be a mechanism of PSO-induced increase in serum insulin. Anti-diabetic and insulin sensitizing effects of $\alpha$ - linolenic acid were also reported in other studies. 


\section{NePhro Protective ACtiVity}

Investigating nephro protective effects of PSO was carried out mainly by Boroushaki et al. In five separated studies, four nephrotoxic agents, mercuric chloride, diazinon, gentamicin, and hexachlorobutadien and cis-platin (under publication) were used and protective effect of PSO was shown. Elevated serum levels of urea and creatinine and urinary levels of glucose and protein as well as histopathological changes in kidney, such as severe tubular necrosis and atrophy, represented acute nephrotoxicity by use of these toxic agents. Inducing oxidative stress by these agents was shown in above mentioned studies by elevated kidney Malon DiAldehyde content (MDA, as a biomarker of oxidative stress) and decreased total thiol content in the kidney.

The use of PSO in these models of nephrotoxicity was accompanied by its protective effects and PSO preserved renal functions and decreased histopathological changes in kidney. Restoration of serum urea and creatinine and decrease in urine glucose and protein were established after PSO treatment. Increasing in total thiol content was seen but was not dose dependent in all studies. Kidney was vulnerable to oxidative stress and each factor that induces this state can be a toxic agent on this organ. PSO due to its high content of polyphenolic compounds is a potent antioxidant. Moreover, hydroxyl benzoic acid derivatives and sterols in PSO have an antioxidant effect and decrease lipid peroxidation.

\section{CONClusion}

Pomegranate (Punicagranatum L.) is a deciduous shrub and native to Iran having ancient culture in this country and Iran is one of the biggest producers of pomegranate in the world. This fruit is used in traditional medicine because of its antibacterial, anti-inflammatory, and alleviative characteristics. Extracts of different parts of pomegranate fruit is rich in phenolic compounds and its rind extract and seed oil have vigorous antioxidant activity. Elagic acid is one of the most important phenolic compounds with antioxidant activity, present in the pomegranate rind extract. Inhibitory effect of pomegranate seed oil on breast and skin cancer has been reported. Use of seed oil and extracts of different parts of pomegranate fruit has been considered in production of phytostrogenic compounds. At the present time, the fruit of pomegranate besides its use as a fruit and having nutritional value is also considered for its pharmaceutical characteristics. This paper is a review on articles and different sources in order to get more familiarity with medicinal characteristics of this fruit.

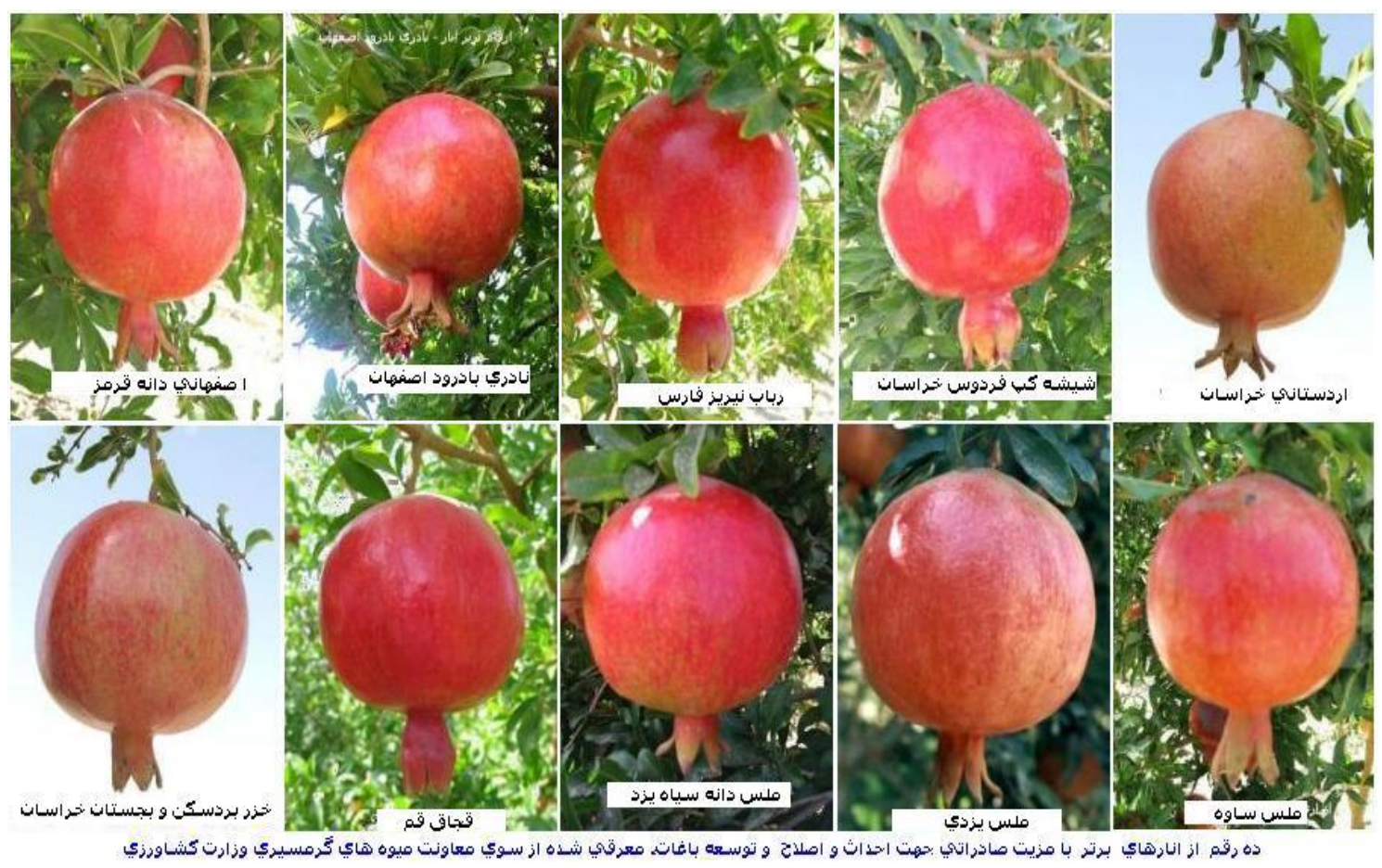

Fig8. Different Pomegranate in Iran

\section{AKNOWLEDGEMENT}

The authors are grateful to the assistance of Dr. Yazdani directure of faculty of desert science in Iran in Semnan University. 


\section{REFERENCE}

[1] Ahmed et al., 2004 J. Ahmed, U.S. Shivhare, G.S.V. Raghavan Thermal degradation kinetics of anthocyanin and visual color of plum puree European Food Research and Technology, 218 (2004), pp. $525-528$

[2] Al-Maiman and Ahmad, 2002 S.A. Al-Maiman, D. Ahmad Changes in physical and chemical properties during pomegranate (Punicagranatum L.) fruit maturation Food Chemistry, 76 (2002), pp. 437-441

[3] Arena et al., 2000E. Arena, B. Calico, E. Macaroni Influence of arytenoids and pulps on the color modification of blood orange juice Journal of Food Science, 65 (2000), pp. 458-460 Avila and Silva, 1999I.M.L.B. Avila, C.L.M. Silva Modelling kinetics of thermal degradation of color in peach puree Journal of Food Engineering, 39 (1999), pp. 161-166

[4] Devin Carroll, Bernard Puget, Brad Higbee, Matt Quist, Octavio Magallenes, Norman Smith, AndreaaGjerde and Ken Schneider. 2006. Pomegranate pest management in the San Joaquin valley.www.aaie.net/IPMinfo/PomegranatePestManagement_002.pdf

[5] Richard Ashton, with Barbara Baer and David Silverstein. 2006. The incredible pomegran. Ate plant and fruit. Third Mellennium Publishing. http://3mpub.com

[6] Robert Hodgson. 1917. The pomegranate. College of Agriculture, Agricultural Experiment Station, Berkeley, California. University of California Press. Bulletin no. 276.

[7] Julian Sauls. 1998. Home fruit production - pomegranate. Texas Citrus and Subtropical Fruits, in association with Texas A\&M University. http://aggiehorticulture.tamu.edu/Citrus/pomegranate.htm

[8] James LaRue. 1977. Growing pomegranates in California. University of California DANR Leaflet 2459.

[9] Gerard Krewer, Thomas Crocker, Paul Bertrand and Dan Horton.

[10] Minor fruit and nuts in Georgia University of Georgia Cooperative Extension Bulletin 992.

[11] Sheets, M.D., Du Bois, M.L., Williamson, J.G. 1994. The Pomegranate University of Florida IFAS extension publication \#HS44

Citation: H. Kheyrodin and S. Kheyrodin" Important of Pomegranates in Iran", International Journal of Research Studies in Agricultural Sciences (IJRSAS), vol. 3, no. 10, p. 9, 2017. http://dx.doi.org/ 10.20431/2454-6224.0310001

Copyright: (C) 2017 Authors. This is an open-access article distributed under the terms of the Creative Commons Attribution License, which permits unrestricted use, distribution, and reproduction in any medium, provided the original author and source are credited. 